\title{
Toxicity of Commercially Available Bar Soap on American Cockroaches (Periplaneta americana)
}

\author{
Mitoriana Porusia ${ }^{1}$, R A P Ratni ${ }^{1}$, S K Dhesi ${ }^{2}$ \\ ${ }^{1}$ Department of Public Health, Universitas Muhammadiyah Surakarta, Pabelan Sukoharjo 57162, Indonesia \\ ${ }^{2}$ School of Geography, Earth and Environmental Science, University of Birmingham, Birmingham B15 2TT, \\ United Kingdom \\ *Corresponding author. Email: mp781@ums.ac.id
}

\begin{abstract}
American cockroach (Periplaneta americana) is a tropical species that can be found in Indonesia and elsewhere. It is of public health importance as it is a vector of some human pathogens. Soap, including bar soap can be used as pesticide for cockroaches. It contains surfactant as an active ingredient. However, the effectiveness of low-cost and commercially available bar soap in controlling these cockroaches has received little attention and is not fully understood. This paper reports the effect of bar soap solution exposure on the American cockroach and determination of the $\mathrm{LC}_{50}$ of solution. The research used True-Experimental design with a Post-Only Control Group. Cockroaches were randomly selected from the rearing cage and the post-test measured cockroach mortality after exposures. The soap solutions were prepared in 4 concentrations (10\%, $20 \%, 30 \%$ and $40 \%$ ), then sprayed directly onto 15 cockroaches with 5 replications. The cockroach condition was observed at $24 \mathrm{hr}$ after treatment and the number of cockroach deaths were counted. Normality data were tested using the Shapiro-Wilk test $(P=0.05)$ and analysed using Friedman's test to determine the difference of variance of concentration. Abbott's test was used to specify the effectiveness of soap solution and the LOGIT test was used to determine $\mathrm{LC}_{50}$. The results suggest that cockroach death occurred after exposure and there was a significant difference between the effectiveness of the soap solution concentrations on mortality $(\mathrm{p}=0.000)$. The Logit analysis indicated that the $\mathrm{LC}_{50}$ of bar soap solution was at $32 \%$. It can be concluded that the soap solution has a killing effect on the American cockroach with $\mathrm{LC}_{50}$ at $32 \%$ after $24 \mathrm{hr}$ of treatment.
\end{abstract}

Keywords: American cockroach, mortality, bar soap solution

\section{INTRODUCTION}

Cockroaches are considered a vector of pathogens, including diarrhoea and typhus to humans. They can also cause phobia, inconvenience, and economic disadvantage. Therefore, cockroach management is essential in terms of minimising impacts on public health and the economy. There are a range of chemical pesticides that can be used to kill cockroaches, but many researchers have recognized the potential for innovation of safer and cheaper insecticides as an alternative for cockroach control. SzumLas [1] suggested that soap and detergent can be used as insecticide that has no residual effect. Soaps have been utilised for this purpose for more than 200 years. Moore et al. [2] reported that soap was used first time in 1787 to control small and soft-bodied insect pests of plants, e.g. whiteflies, scales, and mites.

Even though the historic soap compositions are different from those currently availale soaps, the present soaps are likely to be more effective [3]. It has been found that $100 \%$ mortality of German cockroaches at $2 \%$ concentration of soft soaps (comprised of fatty acid with potassium salts). Soaps that can kill cockroaches are considered as a cheap and low-risk method in domestic settings. Many people in developing countries use bar soap because it is cheaper than liquid soap, and it is readily available. However, there is limited research on the effect of bar soap solution on American cockroaches. Therefore, this research aimed to measure the effectiveness of bar soap solutions on American cockroach mortality.

\subsection{Materials and Methods}

This research used a true-experimental approach, the cockroaches were randomLy taken out from the rearing cage in Institute for Vector and Reservoir Control Research Development Indonesia (B2P2VRP) Salatiga and exposed to bar soap solutions. The experiment used a post-test only and control group design, where the mortality of the cockroach was measured only after treatment and the control group was set up to compare the mortality between the treatment group and the control group. Liquid concentration assay was by using plastic containers with diameter $20 \mathrm{~cm}$ and height $18 \mathrm{~cm}$. The assay containers were coated with butter within $3 \mathrm{~cm}$ of the upper interior rim to prevent cockroaches escaping. The upper end of the container was covered with nylon mesh. Each container consists of fifteen adults of $P$. americana. Periplaneta 
americana were maintained at $31.06+1{ }^{\circ} \mathrm{C}$ and $70+1 \% \mathrm{RH}$ with a photoperiod 12:12 (L:D). There were 5 concentrations of treatment applied; $10 \%, 20 \%, 30 \%, 40 \%$, and $0 \%$ as a control, with 5 replications of each. Spray application was by using hand-held spray bottle containing $100 \mathrm{~mL}$. This research used popular and readily available bar soaps in Indonesia, Lifebuoy®, which contain surfactant as an active ingredient. The bar soaps were shredded, mixed with $100 \mathrm{~mL}$ water, then heated up at 90 ${ }^{\circ} \mathrm{C}$, and stirred until dissolved. After the solutions were cooled down, the cockroaches were thoroughly sprayed with the solution. The condition of the cockroaches was observed at $24 \mathrm{hr}$ and the mortality rate was counted. The lack of leg and antennae movements and the absence of normal response were considered as the sign for knockdown effects.

Normality data were tested using the Shapiro-Wilk test $(P=0.05)$ and analysed using Friedman's test to determine the difference of variance of liquid concentration. Significant differences in the Logit analysis were determined by non-overlap of the $95 \%$ confidence intervals (CI). Abbott's test [4, 5] was used to specify the effectiveness of soap solution and the LOGIT test were used to determine $\mathrm{LC}_{50}$.

\subsection{Our Contribution}

This paper describes the possible use of low-cost commercially available bar soap for American cockroach control. Some popular articles reported that bar soap in a water solution can kill cockroaches, however the concentration and the efficacy have not been statistically measured. This investigation contributes towards understanding the efficacy of bar soap solution to kill $P$. americana and the findings have implications for public health in Indonesia and other tropical countries

\subsection{Paper Structure}

The remainder of the paper is organized as follows. Section 2 explains the mortality of American cockroach exposed to bar soap solutions. The mechanism of body soap active ingredients in killing insects is discussed. This section also tells about compare of other soap toxicity from previous researches. Finally, section 3 concludes the paper and sugest direction for future research.

\section{RESULTS AND DISCUSSION}

During the experiments, cockroaches showed escaping behaviour when exposed to the liquid. The cockroach mortality was not apparent at $2 \mathrm{hr}$ after application. However, $24 \mathrm{hr}$ after application, the death of cockroaches was observed. Some of them were flipping over onto its back and motionless. Both live and dead cockroaches also showed a white residue on their body. Meanwhile, the cockroaches in the control showed no sign of death and no white residue on their body. Thus it was found that the bar soap solution is lethal to American cockroaches. Reza et al. [6] also stated that several dishwashing liquids were toxic against the adult of $P$. americana after $24 \mathrm{hr}$ of exposure.

Table 1 The percentage of Periplaneta americana mortality treated with bar soap solution using 5 levels of concentration

\begin{tabular}{|c|c|c|}
\hline $\begin{array}{c}\text { Concentration } \\
(\boldsymbol{\%})\end{array}$ & $\begin{array}{c}\text { Number of } \boldsymbol{P} . \\
\text { americana }(\mathbf{n})\end{array}$ & $\begin{array}{c}\text { Mortality } \\
\text { rate }(\boldsymbol{\%})\end{array}$ \\
\hline 0 & 15 & 0 \\
\hline 10 & 15 & $20 \pm 0$ \\
\hline 20 & 15 & $30 \pm 0$ \\
\hline 30 & 15 & $47 \pm 0$ \\
\hline 40 & 15 & $60 \pm 0$ \\
\hline
\end{tabular}

Based on the data in Table 1, it was found that the higher concentration of soap solution, the higher mortality of cockroaches. The highest mortality was $60 \%$ that was exposed to the highest concentration of soap solution. There was significant difference of cockroach mortality among soap concentrations $(p=0.00)$. The pesticide formulation will be effective if the Abbot's test result (EI) showed $>50 \%$ of mortality. In this result, the bar soap solution that resulted more than $50 \%$ of death was at concentration $40 \%(\mathrm{EI}=$ $60 \%$ ). Furthermore, the Logit test result showed that the $\mathrm{LC}_{50}$ of soap solution was $32.2 \%$.

The soap solution is likely to remove the protective waxes that cover the insect body and death is likely to occur through excess loss of water. Abbasi et al. [3] and Ware [8] indicated that soap solution may close spiracles of insects, thus inhibit their respiration that results in asphyxiation and mortality. Cockroaches have an oily film and a waxy cuticle hydrocarbon layer throughout on their body surface which is broadened into their tracheae to prevent water loss [9]. Baldwin and Koehler [3] tried to immerse the cockroaches into dishwashing solution and found mortality and bubbles on abdomen spiracles while they were sunk in. The rapid knockdown of soap solution indicates that it acts as nerve toxicants that cause paralysis and death of the cockroaches. Other mode-of-action theories are spiracle blockage, cellular interruption and cuticle desiccation [11- 13]. However, these modes would result in a slower death than observed. Soap solution has low toxicity to mammalians, therefore it has a potential for use as a pest control option in particular environment, such as occupied classroom with children or hospital rooms, kitchen, and rooms used for pets.

This study found that the bar soap solutions were effective on mortality with $\mathrm{LC}_{50}$ at concentration $32.2 \%$. However, some previous research showed different results. Abbasi et al. [3] reported that a spill of commercially available soap in water can kill American cockroaches at 1$2 \%$ of solution. SzumLas [1] stated that the $\mathrm{LC}_{50}$ for certain dishwashing liquid sprayed on German cockroaches was $0.4 \%$ and at concentration higher than $1 \%$ would kill $95 \%$ 
particularly at night. Porusia et al. [15] suggested diminishing the availability of other food source when applying insecticide around cockroach harbourage. solution was lower than $\mathrm{LC}_{50}$ of the bar soap solution to kill cockroaches. On the other hand, Baldwin and Koehler [10] made a low concentration of dishwashing liquid to see mortality on German cockroaches $\left(\mathrm{LC}_{50}>1 \%\right)$ and Reza et al. [6] on P. americana $\left(\mathrm{LC}_{50}>1.5 \%\right)$. However, contact sprays of commercial dishwashing liquid and cleaners were not effective against adult American cockroaches. The type of soaps is likely to explain the differing results. It indicates that spraying treatment using bar soap solutions are not highly lethal in low concentration. Therefore, higher concentrations are needed to reach $\mathrm{LC}_{50}$. Baldwin \& Koehler [10] stated that soap is inexpensive, and low concentrations of soap are needed, but it is likely to vary depending on the brands, type, and formulation of the soaps. This research indicates that bar soap treatment is not fully effective at low concentrations to kill cockroaches.

We found that the higher concentration of bar soap is needed to reach $\mathrm{LC}_{50}$. In contrast, some research found that liquid soaps were effective to kill cockroaches in low concentration $\left(\mathrm{LC}_{50}<1.5 \%\right)[6,10]$. It is presumed that the bar soap formulation does not contain as high concentration of active ingredients as the liquid wash. Therefore, a low concentration of bar soap solution will not be effective to kill cockroaches. This is supported by Baldwin and Koehler [10] who showed that contact spray using liquid wash was not effective to kill American cockroaches. Moreover, the spraying technique mostly exposed the upper body part, particularly wings that have a wax layer which is waterproof, so this technique does not reach spiracles that are mostly found on cockroach's abdomen. The white residue which was appeared on cockroach's upper body might be from the sodium palmate from the bar soap that has a white basic colour.

Bar soap is commercially available in shops and are low-cost common items found in the home. The soap solution could become an option to control the cockroach. Cranshaw [14] suggested that soaps can propose a relatively safe and easy means to control many insect pests. However, there are some limitations including the method of preparation, application technique, and the potential damage to some plants. In this study, it was found that the solutions will be viscous when the temperature drops below $30^{\circ} \mathrm{C}$. Therefore, the solution needs to be heated up to $40^{\circ} \mathrm{C}$ before treatment. Thus, the bar soap solution has some obstacles to use; however, this should be balanced against the costs, risks and controls needed when using chemical pesticides in domestic settings. Further research using other soaps and cleaner liquids need to be tested to understand the different effect on egg and nymph stages of the cockroaches. Additional field tests are needed in the domestic setting to understand how the solutions might be used by the general population.

Although soaps can be utilized as an insecticide, the integrated pest management is more effective to implement to control some insects like cockroaches. This is where some treatments are undertaken to support the cockroach control, such as environmental modification, and diminishing nest and food availability during treatment

\section{CONCLUSION}

Bar soap solution can be lethal to $P$. americana at $\mathrm{LC}_{50}$ $32.2 \%$ after $24 \mathrm{hr}$ of treatment. This finding is of public health significance given the low cost and ready availability of the soap. Additional work is needed with local communities to evaluate use in the field. Further studies with bar soap solutions or liquid soap are needed to find the range of lethal concentration against the egg and nymph stages of cockroaches.

\section{ACKNOWLEDGMENTS}

We thank to B2P2VRP for technical assistance and Universitas Muhammadiyah Surakarta for supports.

\section{REFERENCES}

[1] D.E. SzumLas, Behavioral responses and mortality in German cockroaches (Blattodea: Blatellidae) after exposure to dishwashing liquid, J. Econ. Entomol, 95, (2002) 390-398. DOI: http://10.1603/0022-0493-95.2.390

[2] W.S. Moore, J.C. Profita, C.S. Kochler, Soaps for home landscape insect control, Calif. Agric. 33 (1979) $13-14$

[3] S.A. Abbasi, P. C. Nipaney, R. Soni, Soap solution as an environmentally safe pesticide: for household insects a preliminary investigation, Comp. Physiol.

[4] W. Puenter, Manual for field trials in plant protection second edition, Ciba-Geigy: Agricultural Division, 1981

[5] WHO, Manual on Practical Entomology, Malaria. Geneva: WHO, 1975.

[6] A.M.S. Reza, M.I. Din, S. Parween, Toxicity of dishwashing liquids against the American cockroach, Periplaneta americana L. (Dictyoptera: Blattidae), Univ. J. Zool. Rajshahi Univ. 29 (2010) 51-56

[7] W.S Abbott, A method of computing the effectiveness of an insecticide, J. Econ. Entomol. 18 (1925) 265-267

[8] G.W Ware, The pesticide book, 5th edn. C.A. Thamson Fresno, 2000

[9] P.B. Cornwell, The Cockroaches, Hatchinson, Ecol. (1984) 9 46-48 
[13] W. Olkowski, S. Daar, H. Ollkowski, Commonsense pest control, Taunton Press, Newton, CT, 1996

[10] Baldwin, R.W., Koehler, P.G, Toxicity of Commercially Available Household Cleaners on Cockroaches, Blatella germanica and Periplaneta germanica. BioOne Complete. FES. 90(4) (2007) 703-709, DOI: https://doi.org/10.1653/00154040(2007)90[703:TOCA HC]2.0.CO;2

[11] G.S. Puritch, The toxic effects of fatty acids and their salts on the balsam woolly aphid, Adelges picese (Ratz), Can. J. For. Res. 5 (1975) 515-522

[12] G.W. Ware, The Pesticide Book, Shepard Poorman Graphics, Fresno, CA, 1994.

[14] W.S. Cranshaw, Insect Control: Soap and Detergents. Colorado State University extension, 2008 Chapter 24, Retrieved from https:/extension.colostate. edu/topicareas/insects/insect-control-soaps-and-deterg ents$5-547 /$

[15] M. Porusia, The bait preference of American cockroach (Periplaneta americana): field and laboratory strains, Adv. Sci. Lett. 23 (4) (2017) 3558-3561.

DOI:

https://doi.org/10.1166/asl.2017.9170 